\title{
Locomotor and Exploratory Behaviour in Mice with Treated Oral Artemether Suspension
}

\author{
Koofreh G. Davies ${ }^{1, *}$, Chris topher Ekpe nyong ${ }^{1}$, Justina Nwangwa ${ }^{2}$, Atim B. Antai ${ }^{2}$ \\ ${ }^{1}$ Department of Phy siology, Faculty of Basic Medical Sciences, University of Uyo, Uyo, Nigeria \\ ${ }^{2}$ Department of Phy siology, Faculty of Basic Medical Sciences, University of Calabar, Calabar, Nigeria
}

\begin{abstract}
Previous studies with intramuscular Artemether reveal dose dependent neurotoxic ity with specific concern on the nuclei of the brain stem. This study was aimed at assessing the effect of oral Artemether suspension on locomotor and exploratory behaviour in mice. The study was conducted using a total of 30 mice randomly divided into 3 groups. Group 1 served as the control and was administered with neither drug nor placebo. Groups 2 and 3 were admin istered with $30 \mathrm{mg} / \mathrm{kg} /$ day (low dose) and $60 \mathrm{mg} / \mathrm{kg} /$ day (high dose) respectively of oral Artemether suspension for 17 days. Behavioural tools used were Open Field Maze, ElevatedPlus maze and Light/Dark transition box. Parameters measured were centre square duration/ entries, frequency of rearing, frequency of line crosses, open arm duration / entries and head dips. In the Open Field test, centre square duration and entries were significantly higher in the low dose group but lower in the high dose group compared to the control. The frequency of line crosses in the Open Field test was also significantly lower in the high dose group compared to control. The frequency of rearing was significantly lower in high dose group compared to the control in all the 3 behavioural tools used. There was no significant difference between the control and the experimental mice in the frequency of head dips and open arm duration/entries. In conclusion, oral Artemether causes reduce exploratory and locomotor activity.
\end{abstract}

Keywords Locomotor Activity, Exp loratoryactivity, Artemether, Anti-Malarial, Mice, Open Field Maze

\section{Introduction}

\subsection{Background Infor mation}

The Qinghaosu (artemisinin) and its derivatives are a group of antimalarial drugs isolated from the leaves of a medicinal herb, the Artemisia annua[1]. Artermisinin is the most rapid acting class of antimalarial drugs for both uncomplicated and severe malaria[2]. The discovery of artermisinin for malaria therapy by Chinese scientists in the 1970 s was one of the greatest discoveries in medic ine in the 20th century. Repres enting a new c lass of antima larialagents, artemisinin is a sesquiterpene lactone characterized by an endoperoxide bridge essential for its antimalarial activity[3] with a chemical structure different from any other drug. It acts against the asexual stage gametocytes and block the sexual stage[3]. Chemical modifications of artemisinin (reduction plus esterification) have enabled more potent and more soluble derivatives to be obtained, with improved bioavailability[4][5]. Among these different derivatives is artemether, methyl ether of dihydroartemisinin.

* Corresponding author:

kudaves2000@yahoo.com (Koo freh G. Davies)

Published online at http://journal.sapub.org/neuroscience

Copyright (C) 2012 Scientific \& Academic Publishing. All Rights Reserved
Artemether is characterized by its novel structure and unique antimalarial action, which are totally different from the conventional antimalarial drugs[2]. Artemether is very effective against multi drug resistant malaria. An animal pharmacodynamics showed that artemether is a strong schizonticide. Parasitaemia clearance occurs rapidly with stable efficacy after administration[2]. It is also effective against Chloroquineresistant Plasmodium falciparum malaria.

Although Artemisininshave been widely reported to be safe clinically, some studies (animal studies) have shown that these drugs are neurotoxic. Neurotoxicity is commonly seen with parenteral route and prolonged admin is tration. Oil soluble derivatives of artemisimins are reported to be more toxic than the water soluble forms. These compounds have been shown to produce an unusual selective pattern of damage to certain brain stem nuclei i.e. precerebellar nuclei of the medulla oblongata and particularly those involved in auditory processing and vestibular functions i.e. the trapezoid nucleus, the gigantocellu lar reticular nucleus and the inferior Cerebellar peduncle[6]. In the rat, the target brainstem nucleus consistently and most severely affected is the nucleus of the trapezoid body[7][8]. Changes in the affected neurons were loss of Nissl substance, perikaryonal swelling, margination of the nucleus (nucleus accentricity), nucleolar changes, and increased perikaryonal eosinophilia 
with occasional clumping of eosinophilic debris[6].

Exploratory behavior refers to the tendency to investigate a novel environ ment. It is considered a motivation not clearly distinguishable from curiosity. The concept of exp loration is closely associated with that of novelty[9], which may involve some quality never previously experienced or familiar items arranged in unfamiliar way. Okeefe and Nadel (1978) defined novelty within the framework of their cognitive map theory as follows "an item or place is novel if it does not have a representation in the locale system" and exploration as adirect response of the animal to the detection of a mismatch by the locale system". The locale system being the cognitive mapping system, presumably located in the hippocampus that contain mental representations of stimuli previously perceived. In other words, the hippocampal system supposedly signals a lack of information about the current environment. Consequently, one of the processes thought to be associated with exploratory activity is what is called latent learning or exploratory learning[10][11]. Thus the animal acquire information about their environment[12]

Till date however, there has not been any study evaluating effects of prolonged administration of Artemether on Loco motor and Explo ratory behaviour.The aim of this study therefore, was to evaluate the effects of Artemether Loco motor and Explo ratory behaviour.

\section{Materials and Methods}

\subsection{Animal Care}

Adult albino mice, thirty in number were housed singly in metabolic cages under standard laboratory conditions and were fed with pellet feed (Vital feed and flour mill limited, Edo, Nigeria). All animals were housed in cross ventilated room (temp $22 \pm 2.5$; humidity $65 \pm 5 \%$ and $12 \mathrm{~h}$ light $/ 12 \mathrm{~h}$ dark cycle). A period of one week was allowed for acclimatization.

\subsection{Drug Preparation}

Oral Artemether suspension marketed under the brand name "Gvither" manufactured by Bliss GVS Pharmaceutical limited of India was purchased from a reputable pharmacy in Uyo, Akwalbom State, Nigeria. The suspension was reconstituted by adding $100 \mathrm{ml}$ of water to each bottle (which contained $300 \mathrm{mg}$ of Artemether). The bottle was then tightly closed, inverted and shaken until all the powder was dispersed. This yielded a stock solution of $3 \mathrm{mg}$ of arte mether per ml. Each reconstituted suspension was stored in a cool dry place at roo $\mathrm{m}$ te mperature $\left(25^{\circ} \mathrm{C}\right)$ and used within 7 days.

\subsection{Animal Treatment}

Thirty (30) Alb ino Mice were randomly separated into 3 groups. Group 1 served as control and received only feed and water. Groups 2 and 3 respectively received $30 \mathrm{mg} / \mathrm{kg}$ (low dose) and $60 \mathrm{mg} / \mathrm{kg}$ (high dose) of oral arte mether suspension daily for 17 days by gavage

\subsection{Open Field Maze (OFM)}

The open field is constructed of plywood and measures 72 $x 72 \mathrm{~cm}$ with $36 \mathrm{~cm}$ high walls. The floor and three walls of the $\mathrm{OF}$ are made from $2-\mathrm{cm}$ thick plywood that has been painted white. The fourth wall is made of clear Plexig las so that the mice can be observed from the front of the apparatus as well as fro $m$ the top. Blue lines painted on the floor divide the open field into forty-nine $5 \times 5 \mathrm{~cm}$ squares, and these lines are used to assess locomotor activity. The centre square $(15 \times 15 \mathrm{~cm})$ is formed from the four inner squares and this square is highlighted with a black marker. A sheet of clear Plexig las covers the floor.

All animal testing was conducted under diffuse lighting conditions via a $60-$ Watt white light bulb.

\subsubsection{Procedure}

Mice were carried to the test room in their ho me cages and tested one at a time. The mice were scooped up in a small plastic container from their home cages and placed randomly into one of the four corners of the open field. They were allowed to explore the apparatus for 5-minutes while taking scores of their behaviours. After the 5-minutes test, the mice were scooped up from the open field with the plastic container and returned to their home cages. The open field was cleaned with $70 \%$ ethyl alcohol and permitted to dry between trials. The behaviours scored included:

1. Nu mber of line crossing; frequency with which the mice crossed one of the grid lines with all four paws.

2. Centre square entries; frequency with which the mice crossed one of the red lines with all four paws into the central square.

3. Duration of stay in the central square.

4. Rearing frequency and duration.

\subsection{Elevated Pl us-Maze (EPM)}

The Elevated Plus-Maze was built according to the description of Lister (1987). The apparatus is in the configuration of a + and comprised two open arms $(25 \times 5 \times$ $0.5 \mathrm{~cm})$ across from each other and perpendicular to two closed arms $(25 \times 5 \times 16 \mathrm{~cm})$ with a centre platform $(5 \times 5 \times$ $0.5 \mathrm{~cm})$. The open arms had a very small $(0.5 \mathrm{~cm})$ wall to decrease the number of falls, whereas the closed arms had a high $(16 \mathrm{~cm})$ wall to enclose the arm[14]. The entire apparatus was $50 \mathrm{~cm}$ above the floor. The apparatus was made of white transparent Plexiglas materials.

\subsubsection{Procedure}

Mice were carried into the test room in their home cages and were handled by the base of their tails at all times. Mice were placed in the central square of the Plus-Maze facing an open arm and were then allowed to explore the apparatus for 5 minutes. The maze was then cleaned with a solution of 
$70 \%$ ethyl alcohol and allowed to dry between tests. Behaviours scored were:

i . Open Arm Entries: Frequency with which the animal entered the Open arms. All four of the mouse's paws should be in the open arms to be regarded as an entry.

ii. Open Arm Duration: Length of time the animal spent in the open arms.

iii. Head Dipping: Frequency with which the animal lowered its head over the sides of the open arms towards the floor.

iv. Rearing: Frequency with which the animal stands on its hind legs or leans against wall of the maze with front paws.

\subsection{Light-dark Box (LDB)}

The light-dark box $(45 \times 27 \times 27 \mathrm{~cm})$ is made of plywood and consists of two compartments of unequal size as described by Costallet al. (1989)[13]. The small compartment $(18 \times 27 \mathrm{~cm})$ is painted black $(2 / 5$ of the box $)$ and the larger compartment $(27 \times 27 \mathrm{~cm})$ is painted white (3/5 of the box). These compartments are connected by a door $(7.5 \times 7.5 \mathrm{~cm})$ located at floor level in the centre of the wall between the two compartments. The floor is divided into $9 \times 9 \mathrm{~cm}$ squares and is covered with Plexiglas. Both compartments are covered with lids of clear Plexiglas. A 60 -Watt table lamp located $40-\mathrm{cm}$ above the centre of the white compartment provides bright illumination of white light. The apparatus was located in a 2 x $5 \mathrm{~m}$ laboratory room.

\subsubsection{Procedure}

Mice were carried into the test room in their home cages. The procedure was as described by Costallet al. (1989)[13]. Mice were picked up by the base of their tail and placed in the centre of the white compartment facing the door and allowed to explore the apparatus for 5-minutes.The maze was then cleaned with a solution of $70 \%$ ethyl alcohol and allowed to dry.

Behaviours scored were:

1. Line crosses: number of times the animal crossed a line drawn on the floor.

2. Rearing: frequency with which the animal stands on hind legs or leans against walls of the box with front paws.

\section{Results}

\subsection{Open Field Maze (OFM)}

Centre square duration and frequency were significantly higher in mice treated with $30 \mathrm{mg} / \mathrm{kg}$ of Artemether (low dose group) but lower in mice treated with $60 \mathrm{mg} / \mathrm{kg}$ of Artemether (high dose group) than in the control. The frequency of rearing was significantly higher in high dose group compared to control $(\mathrm{p}<0.05)$. There was no difference between the low dose group and the control in the frequency of rearing. The frequency of line crosses was significantly lower in high dose group compared to control.

\subsection{Elevated Plus Maze (EPM)}

Frequency of rearing was significantly lower in the high dose group compared to the control $(p<0.05)$. However, the frequency of Head dips, open arm entries and duration in the experimental groups were not significantly different from that of the control.

\subsection{Light and Dark Transition Box (LDB)}

The frequency of rearing was significantly higher in the high dose group compared to control $(p<0.05)$. There was no difference between the low dose group and the control. The frequency of line crosses was significantly lower in high dose group compared to control

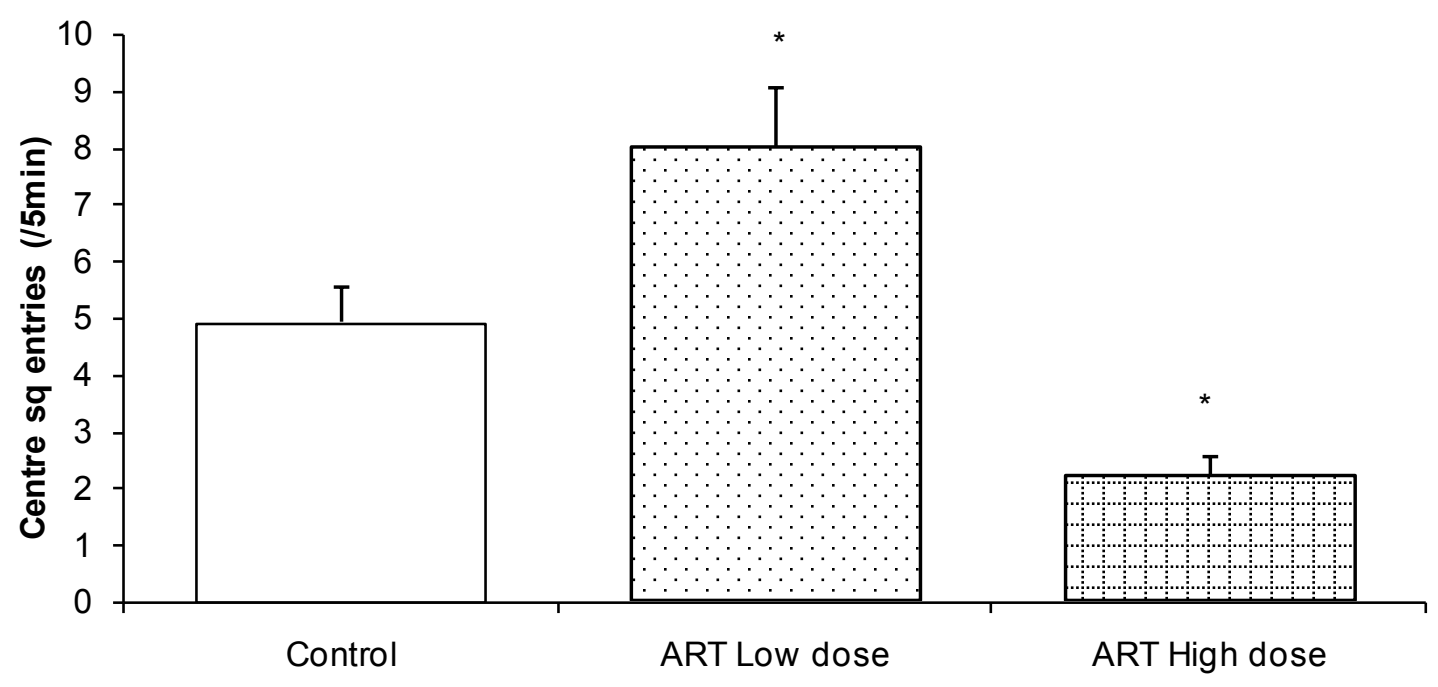

Figure 1. Comparison of the frequency of centre square entries in the open field testin mice following oral administration of $30 \mathrm{mg} / \mathrm{kg}$ (low dose) and $60 \mathrm{mg} / \mathrm{kg}$ Art emether (ART) 


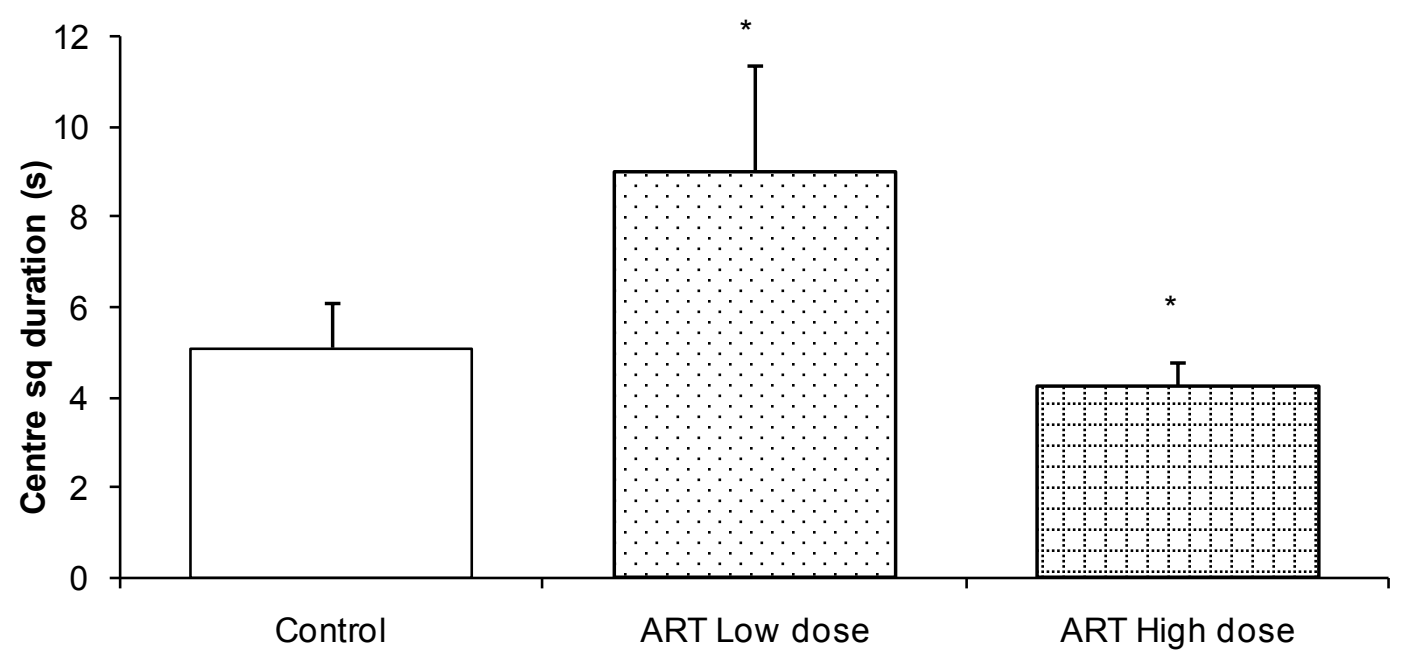

Figure 2. Comparison of centre square duration in the open fieldt est in mice following oral administrat ion of $30 \mathrm{mg} / \mathrm{kg}$ (low dose) and $60 \mathrm{mg} / \mathrm{kg}$ Art emether (ART)

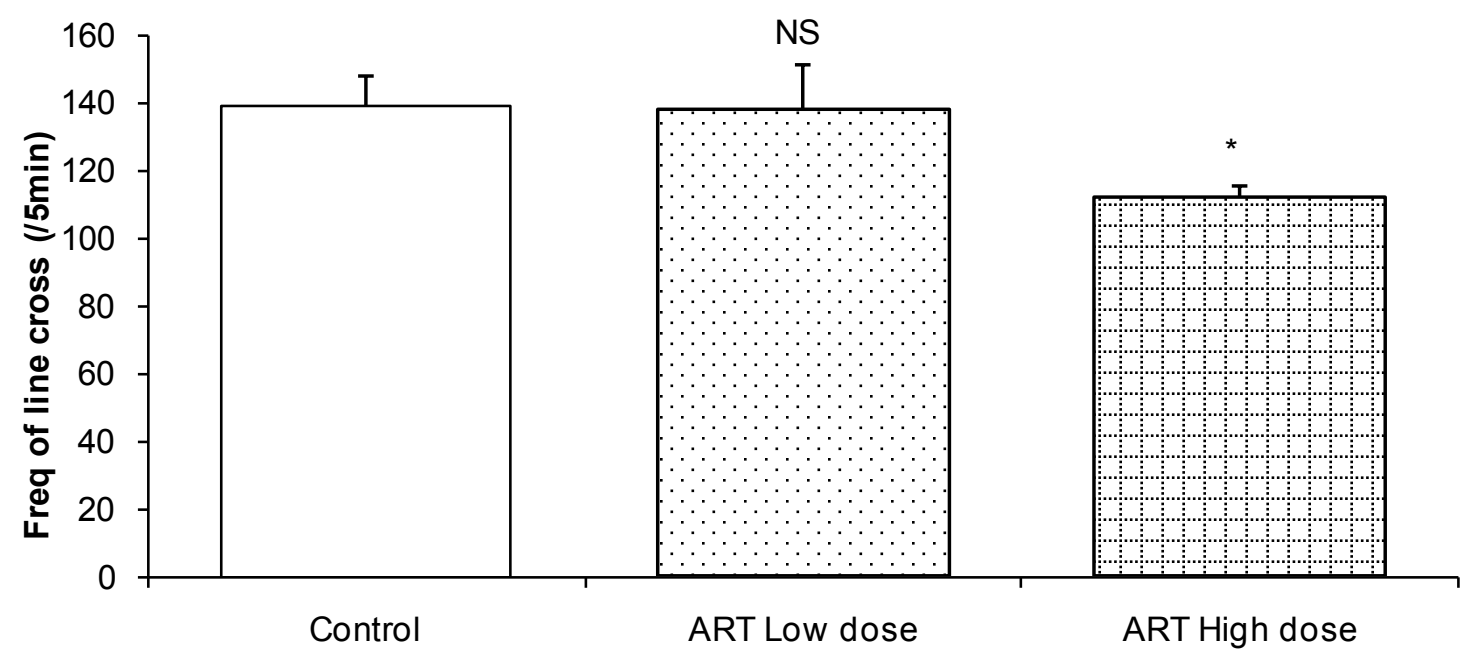

Figure 3. Comparison of the frequency of line crosses in the open field testin mice following oral administration of $30 \mathrm{mg} / \mathrm{kg}$ (low dose) and $60 \mathrm{mg} / \mathrm{kg}$ Artemether (ART)

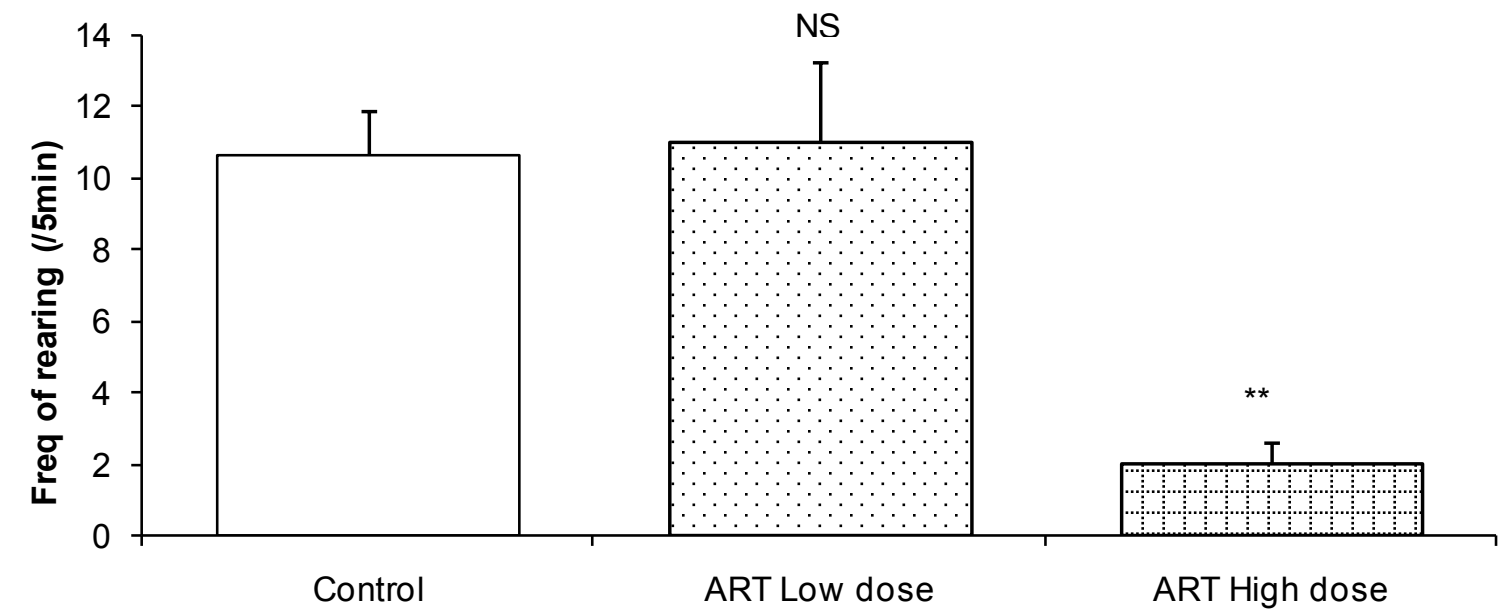

Figure 4. Comparison of the frequency of rearing in the open field testin mice following oral administration of $30 \mathrm{mg} / \mathrm{kg}$ (low dose) and $60 \mathrm{mg} / \mathrm{kg}$ Artemether (ART) 


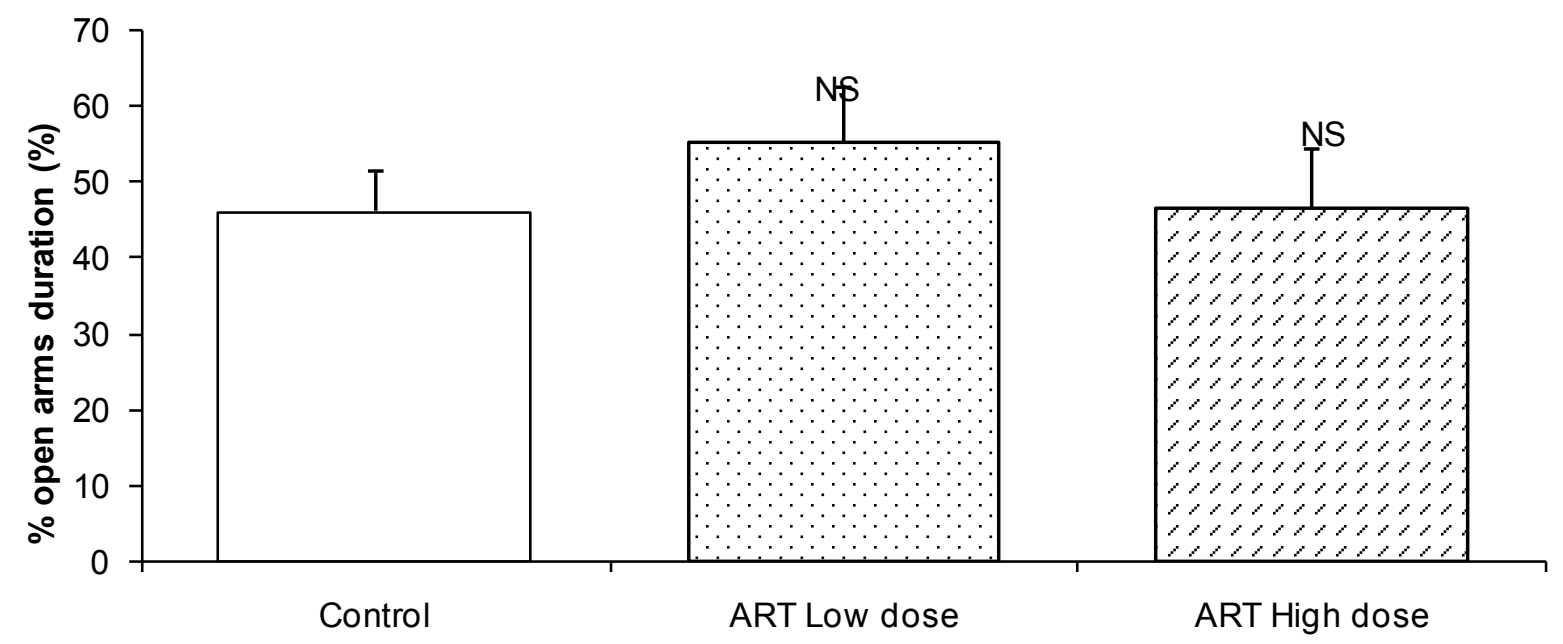

Figure 5. Comparison of duration of open arm duration in the Elevated PlusMazein mice following oral administration of $30 \mathrm{mg} / \mathrm{kg}$ (low dose) and $60 \mathrm{mg} / \mathrm{kg}$ (high dose) Artemether (ART)

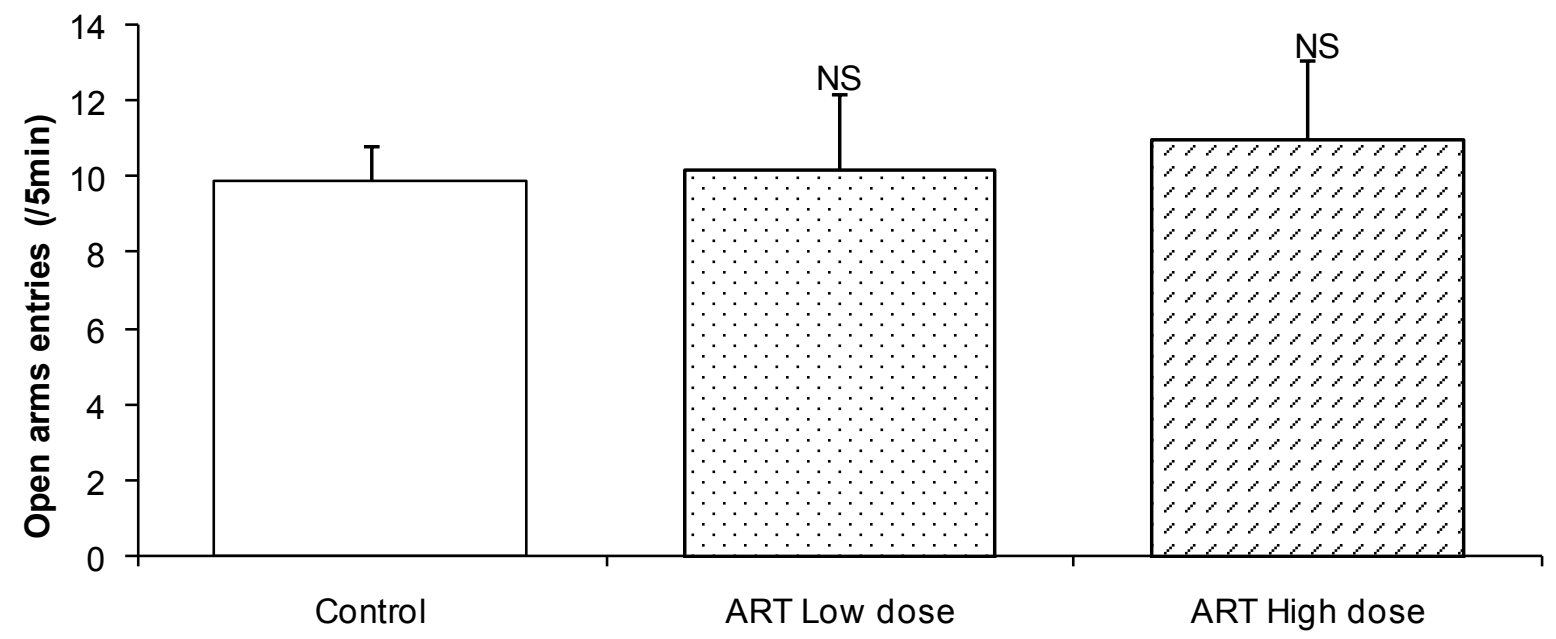

Figure 6. Comparison of the frequency of open arm entries in the Elevated PlusMaze in mice following oral administration of $30 \mathrm{mg} / \mathrm{kg}$ (low dose) and $60 \mathrm{mg} / \mathrm{kg}$ (high dose) Artemether (ART)

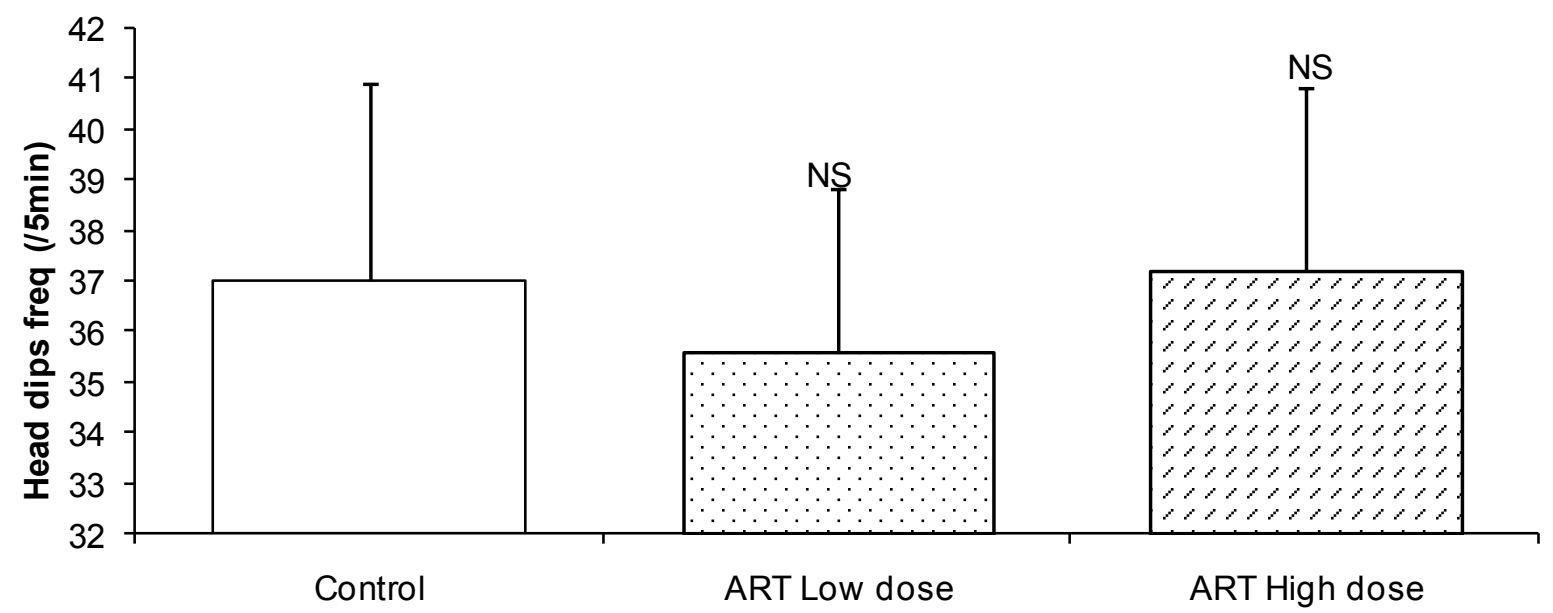

Figure 7. Comparison of the frequency of Head dips in the Elevated PlusMaze in mice following oral administration of $30 \mathrm{mg} k \mathrm{~kg}$ (low dose) and $60 \mathrm{mg} / \mathrm{kg}$ (high dose) Artemether (ART) 


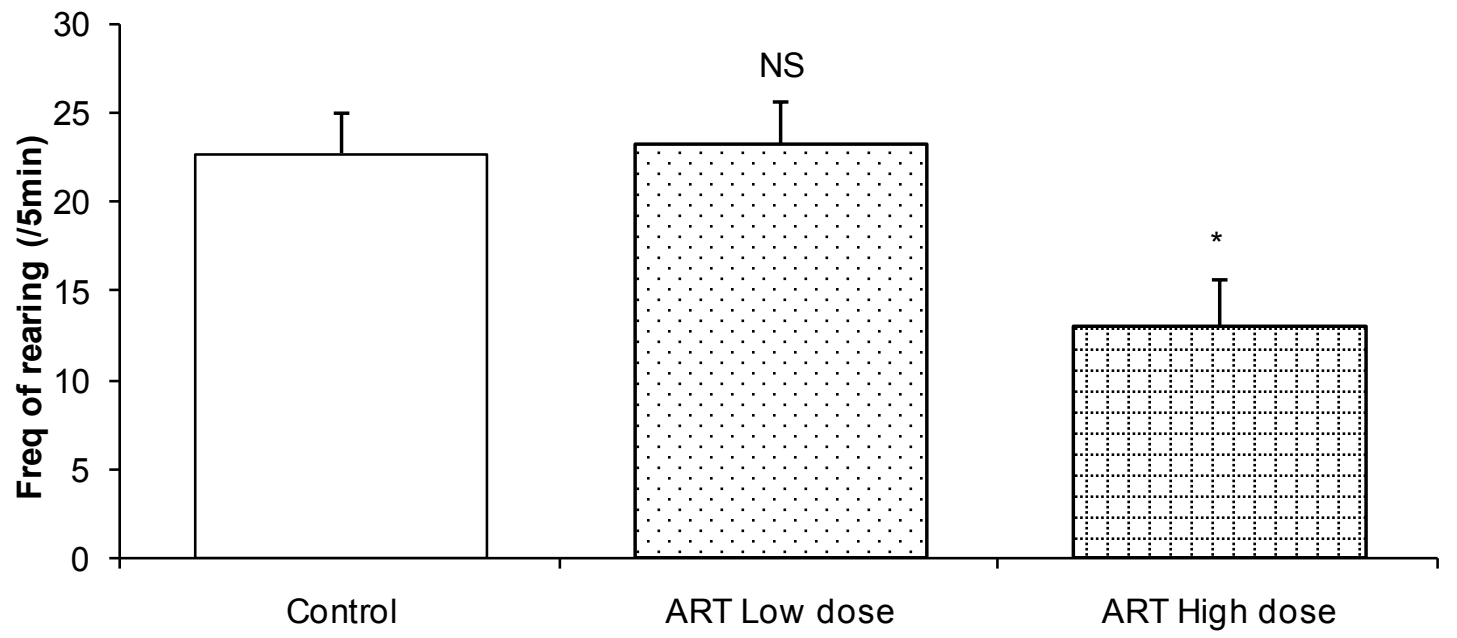

Figure 8. Comparison of the frequency of rearing in the Elevated PlusMaze in mice following oral administration of $30 \mathrm{mg} / \mathrm{kg}$ (low dose) and $60 \mathrm{mg} / \mathrm{kg}$ (high dose) Artemether (ART)

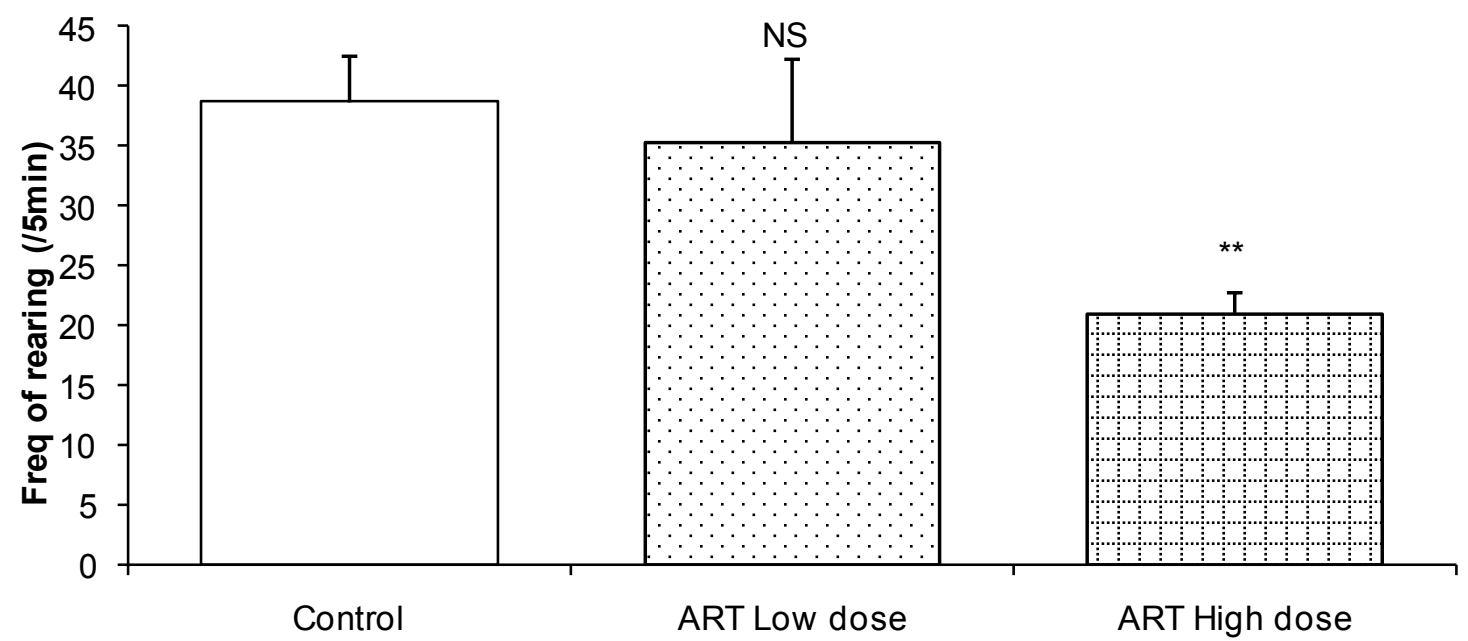

Figure 9. Comparison of the frequency of rearing in the Light and Dark Transition boxin mice following oral administration of $30 \mathrm{mg} / \mathrm{kg}$ (low dose) and $60 \mathrm{mg} / \mathrm{kg}$ (high dose) of Artemether (ART)

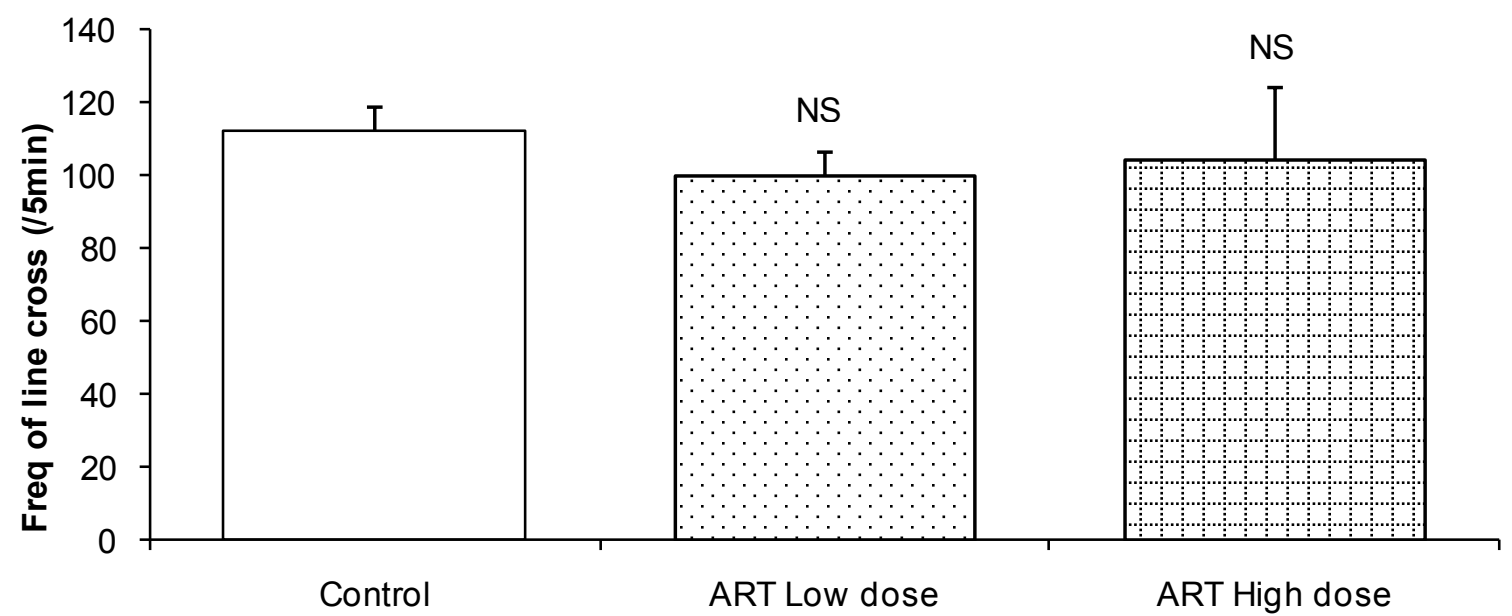

Figure 10. Comparison of the frequency of line crosses in the Light and Dark Transition boxin mice following oral administration of $30 \mathrm{mg} / \mathrm{kg}(\mathrm{low}$ dose) and $60 \mathrm{mg} / \mathrm{kg}$ (high dose) of Art emether (ART) 


\subsection{Statistical Analysis}

Data collected were expressed as mean \pm standard error of mean (SEM), analysis of variance (ANOVA) was used for analysis. Values of $\mathrm{P}<0.05$ were regarded as significant. Statistical analysis was done with the aid of computer software SPSS and Excel from Windows XP (Brain Series, China).

\section{Discussion}

This study was designed to assess the effect of long-term administration of oral Artemether on Locomotorand exploratory behaviour of Mice. The tools used were Open field Maze, Light /Dark transition box and Elevated Plus Maze. Thesebehavioural tools are usually employed to simu ltaneously ass ess Locomotion, Exploration and Anxiety. Behaviour such as line crosses and rearing are used as measures of Locomotion and Exploratory activity. A high frequency of these parameters indicates increased locomotion and Exploration. The frequency of line crosses measures the horizontal loco motor behaviour and represents the horizontal covered[15].

In the Open Field test, the frequency of line crosses was significantly lower in mice treated with $60 \mathrm{mg} / \mathrm{kg}$ of oral Artemether compared to the control group $(p<0.05)$. However, the frequency of line crosses was not affected in the other 2 behavioural tools employed (Elevated plus maze and Light/Dark box). The reason why this parameter was reduced in OFM and not in DLB is not clear. It is possible that this may be due to habituation.Since LDB test was conducted 2 days after the OFM test, the init ial increase in an anxiety resulting in reduced movement may have habituated, causing no change in the parameter.

It is also conceivable that horizontal motor activityimpairment may be starting to manifest at this dose level $(60 \mathrm{mg} / \mathrm{kg})$. However, this deduction does not agree with our earlier findingwhich showed no sensory-motor deficit in Water Mazeexperiment in mice treated with same dose levels of Arte mether and for longer duration[16].

Furthermore, the drug might have caused this effect by reducing motivation to walk and not necessarily affecting the motor system.

Rearing measures exploratory behaviour or otherwise vertical loco motor activity. When rearing, the animal stands upright on the hind-legs often using the tail as support while visually exploring the environment[17]. Rearing allows the mouseto obtain information about the environment and appears to represent exploration. In this study rearing was significantly lower in the group treated with $60 \mathrm{mg} / \mathrm{kg}$ of oral Artemether compared to the control. This finding was observed in all the three behavioural tools used. The mechanis $m$ which the drug caused reduce frequency of rearing in this study is not known, but it stands to reason that the drug may do this by causing reduce motivation to rear. Another possible explanation is that the drug may affect balance, and as such,upright posture. Earlier studies have shown that some nuclei of the Brainstem, especially those involved in auditory processing and vestibular reflexes, were selectively damaged by high and prolonged Artemisinin administration[8], resulting in abnormal gait and loss of balance.

The centre square duration and entries were lower in mice treated with $60 \mathrm{mg} / \mathrm{kg}$ of Artemether. This finding is in tandem with those elucidated above and further buttresses the fact that oral artemether at this dose level $(60 \mathrm{mg} / \mathrm{kg})$ impairs exploration. Surprisingly, the group treated with $30 \mathrm{mg} / \mathrm{kg}$ showed significant increase in both central square duration and entries. This finding is not clear.

\section{Conclusions}

Oral Artemether at the dose of $60 \mathrm{mg} / \mathrm{kg}$ causes reduced exploration and locomotor activity in mice. Though this finding may not be extrapolated directly to humans, it is important to bear this in mind especially in the light of ro le as a possible anti- cancer drug.

\section{REFERENCES}

[1] Tu, Y. (2011). The discovery of (ginghaosu) and gifts from Chinese Medicine. Nature Medicine, 17(10): 1217-1220.

[2] Adekunle, A. S., Falade, C. O., Agbedana, E. O. and Egbe, A. (2009). Assessment of side-effects of administration of artemether in humans.Biology and medicine, 1(3): 15-19.

[3] Cui, L. and Su, X. (2010). Discovery, Mechanisms of action and combinatino therapy of artemisinin.Expert Review of Antiinfectious therapy, 7(8): 999-1013.

[4] Basra, A. S. (2005). Handbook of medical Plants, 2nd end. CRC Press

[5] Chekem L. Wierueki, S. (2006). Extraction of artemisininsand synthesis of it derivatives artesunate and artemether. Med Trop.(Mars), 66(6): 602-5.

[6] Abdulazeez, A. A., Owoeye, O. and Ejiwunmi, A. B. (2006). The Neurotoxic Effects of Artemether on the cy toarchitecture of the Trapezoid Nuclei of Adult male Wistar rats (Rattusnovegicus). International Journal of Morphology, 24(4):535-540

[7] Li, G. Q., Mog, S. R., Si, Y. Z., Kyle; Gettayacamin, M. and Mihous, K. (2002). Neurotoxicity and efficacy of arteether related to its exposure times and exposure levels in rodents. American Journal of Tropical Medicine and Hygiene, 66(5): 516-25.

[8] Nontprasert, A., Pukviltayakanee, S., Dondrop, A. M., Clemens, R., LovaveeSuwan, S., White, N. J. (2000). Neuropathologic toxicity of artemisinin deriviatives in a mouse model.American Journal of Tropical Medicine and Hygiene, 62(3): 409 - 412.

[9] Barnett, S.A. and Cowan, P.E. (1976) Activity, exploration, curiosity and fear: An ethological study, Interdisc. Sci. Rev.1: 43-62. 
[10] O'Keefe, J. and Nadel, L. (1978). The Hippocampus as a Cognitive Map, Clarendon Press, Oxford.

[11] Renner, M. J. (1988). The role of behavioural topography during exploration in determining subsequent adaptive behaviour.International Journal of Comparative Psychology. 2:43-56

[12] Crusio, Wim E. (1995) Natural Selection on Hippocampal Circuitry Underlying Exploratory Behaviour in Mice: Quantitative-Genetic Analysis. In: E. Alleva, A. Fasolo, H.-P. Lipp, L. Nadel and L. Ricceri (eds.), Behavioural Brain Research in Naturalistic and Seminaturalistic Settings. NATO Advanced Study Institutes Series D, Behavioural and Social Sciences, Kluwer Academic Press, Dordrecht, THE NETHERLANDS, p. 323-342, 1995.

[13] Costall, B., Jones, B.J., Kelly, M.E., Nay lor, R.J. \& Tomkins, D.M. (1989). Exploration of mice in a black and white test box: Validation as a model of anxiety. Pharmacology, Biochemistry and Behavior, 32:777-785.
[14] Guy B Mulder, Kathleen Pritchett in Contemporary topics in laboratory animalscience. American Association for Laboratory Animal Science (2004)

[15] Kelley, A.E., Cador, M., and Stinus, L. (1989) Exploration and its measurement. A psychopharmacological perspective, in A.B. Boulton, G.B. Baker, and A.J. Greenshaw (eds.), Neuromethods, Volume 13: Psychopharmacology, Humana Press, Clifton, pp. 95-144.

[16] Davies K. G., Edagha, I. A., Peter, I. P., John, E. O. and Eme E. Osim (2012). Effect of oralartemether suspension on spatial memory.European Journal of Scientific Research. 82(4):499-505

[17] Van Abeelen, J.H.F. (1970) Genetics of rearing behavior in mice, Behav. Genet.1, 71-76.

[18] Walsh, R. N. and Cummins, R. A. (1976).The Open Field test.A critical review.Psy chological Bulletin. 83:482-504 